\title{
Chapter 5 \\ Reflections on Realistic Mathematics \\ Education from a South African \\ Perspective
}

\author{
Cyril Julie and Faaiz Gierdien
}

\begin{abstract}
The project Realistic Mathematics Education in South Africa (REMESA) was introduced in South Africa during a period when curriculum changes were introduced to fit the educational ideals of the 'new' South Africa. In this project, modules based on Realistic Mathematics Education were developed by a team comprising staff from the Freudenthal Institute and the Mathematics Education sector of the University of the Western Cape. The modules were implemented in classrooms. In our chapter, we reflect upon the appropriation by practicing teachers of two modules. Teachers viewed the module Vision Geometry with scepticism whilst the module Global Graphs was more readily accepted. The appropriation was thus differential. In current school mathematics policy documents and learning materials, the major ideas of the module Vision Geometry are virtually invisible. The ideas from the module Global Graphs are more visible. This can be ascribed to the prominence of graphical representations in South African school mathematics curricula. The two instances point in the direction that the proximity of innovative approaches to the operative curriculum plays an important role with respect to teachers' adoption of the resources for their practice.
\end{abstract}

Keywords Curriculum change - Innovation and operative curriculum $\cdot$ Vision geometry $\cdot$ Global graphs $\cdot$ Functions, tables and graphs

\subsection{Introduction}

The project Realistic Mathematics Education in South Africa (REMESA) was introduced in line with local and international or global currents in mathematics education.

\footnotetext{
C. Julie ( $\varangle)$

University of the Western Cape, Cape Town, South Africa

e-mail: cjulie@uwc.ac.za

F. Gierdien

University of Stellenbosch, Stellenbosch, South Africa

e-mail: faaiz@sun.ac.za 
It took root during a period that saw the first democratic and non-racial elections in South Africa in 1994. This was a period marked by political efforts on behalf of the newly elected South African government to rid the country of its Apartheid past. REMESA thus came at a time where the new state had to work on establishing its legitimacy in the educational sector especially, which was not the case in the past. Not surprisingly, the mid to late 1990s witnessed intense education reform efforts. For example, the National Education and Training Forum (NETF) was formed in 1992 to address the deteriorating schooling system inherited from the Apartheid past. An active sub-committee of the NETF, the Curriculum Technical Sub-Committee (CTSC), embarked on short-term syllabus revision of the different 'field' committees (mathematics, natural sciences, etc.) and 'phase' committees (junior primary, senior primary and secondary) (see Jansen, 1999). In short, these committees had the brief to remove outdated, inaccurate and insensitive content present in the school syllabuses. In addition, during this period there were consultations and negotiations with stakeholders such as student organisations and the South African labour movement. What we ultimately witnessed was the adoption of a school curriculum organised around outcomes-based education. School subjects became known as 'learning areas' wherein there was cross-curricularisation around particular, desired outcomes. Also, at a global level, from the 1960s onwards, there was a quest for cross-curricular work in school mathematics (Julie, 1998). In the case of outcomes-based education, this quest became much more explicit (Julie, 1998). Examples of this global trend can be traced to texts such as "Links Between Mathematics and Other Subjects" (Selkirk, 1982) and "Integrating Mathematics into the Wider Curriculum" (Roper, 1994). The connection to local/national, global forces and cross-curriculum is evident in REMESA publications (Julie et al., 1998; Verhage et al., 2000).

At the (initial) teacher education level, REMESA was semi-inspired by the problem-centred approach at the University of Stellenbosch (Hiebert et al., 1996) which also had underpinnings of Realistic Mathematics Education (RME). Freudenthal's (1973) seminal text, Mathematics as an Educational Task, was compulsory reading in graduate courses in mathematics education at University of the Western Cape (UWC) and University of Stellenbosch.

During this period, school mathematics was accorded priority based on the internationally-held belief that quality teaching and learning of school mathematics will contribute towards the economic development of a country. This belief relates to the notion that quality mathematics teaching and learning fosters processes such as group solution-seeking to problems, creativity and the application of mathematics to extra-mathematical situations such as natural, economic, health, cultural and social phenomena. For the South African situation, these were deemed important attributes which should be developed in schools for the country's progress. With these ideas in mind, the Mathematics Education division of UWC entered into a partnership with the Freudenthal Institute (FI) with the objective of introducing RME as a viable approach for school mathematics to work towards the outcomes sought for schooling in the country.

There was thus an awareness of the underlying ideas of RME which provided fertile soil for the partnership entered into. 


\subsection{The Essences of REMESA}

Following the developmental research approach of the FI for the development of local instructional theories, an essential aspect of REMESA was that there must be some alignment of the work done by the project and the operative school mathematics curriculum. The importance of this element is linked to the issue of immediacy in the sense that the differential adoption of a teaching innovation by teachers is highly driven by their sense of the direct applicability of the ideas distributed by the innovation for their practice. Linked to the aforementioned element was that there should be learning resources epitomising RME. These resources should be classroom-tested so that there is evidence of its applicability for the South African context. They should also be in a form that allowed for easy distribution to schools in socially and economically deprived environments in South Africa, which was the empirical domain in which the sector Mathematics Education at UWC operated. A last important component was that a capacity-building element should accompany the project in order to ensure sustainability at the culmination of the project. To realise this, a group of post-graduate students was recruited to research aspects of the implementation of RME in classrooms. The project ran for approximately five years.

A variety of modules (Vision Geometry; Global Graphs; Functions, Tables and Graphs; and The Exponential Function) was developed by a team comprising staff from the FI and the sector Mathematics Education at UWC. The FI staff spent time in South Africa for the development of the modules. The reflection in this chapter focuses on the development of two modules: Vision Geometry and Global Graphs. They were conveniently selected in order to guide discussion on some of the issues involved in adaptation and adoption of instructional design emanating from an educational environment in a highly developed context for use in a late-developing one. The first module discussed below had less influential currency than the second one and reasons for these are discussed.

\subsection{Vision Geometry}

Vision Geometry was the first module developed and developmentally researched in a classroom (Lewis, 1994). This module was particularly chosen due to problems learners experience with geometry in South Africa. From the RME perspective, developing learning resources where learners are provided with activities where they experience mathematics from Freudenthal's dictum that reality is the source of and the domain of application of mathematics, it was deemed that vision geometry was a sound way manifest the RME approach. The elements or content of vision geometry were: lines of sight, the influence of position when an object is observed, angle of sight, perspective (views), two-dimensional representations of three-dimensional objects and constructions emanating from lines of sight. These elements were encapsulated in 
activities for learners. One such activity was the 'Thumb jump'. The activity starts with the teacher drawing a line on the chalkboard. A learner is called to the front of the class. With her/his arm stretched out and one eye closed, the thumb has to be positioned so that it is in line with the line drawn on the chalkboard. Once this is fixed, the thumb has to be held in that position, the closed eye is opened and the other eye closed and the position of the line has then to be indicated and drawn. Figure 5.1 depicts the worksheet dealing with the 'Thumb jump' activity.

In Fig. 5.1 the horizontal and skew lines represent the chalkboard. The instructions (which were in Afrikaans) were:

(1) Draw the position of the second line ('streep' in Afrikaans) on the chalkboard. Use a line of sight. [In the teacher guide teachers were encouraged to introduce the concept of 'line of sight'.]

(2) Draw the position of your thumb.

(3) Draw the position of the second line. Stand in a position twice your distance from the first line and draw the second line. What do you observe about the last two lines you have drawn?

Figure 5.2 illustrates a learner doing the 'Thumb jump' activity and Fig. 5.3 shows an example of the drawings that were made when doing this activity. In Fig. 5.3a it can be observed that a learner first drew the entire person holding the stick and illustrated his/her position. After the module designers, who were observing the classroom implementation, alerted learners that they should do the drawing as seen from above, Fig. 5.3b resulted.

An example of a typical response learners offered for the observed phenomenon is given in Fig. 5.4. As is clear from this, the explanations focused on features of the thumb and the seeming 'jumping action' of the eye ("your eye jumps still further").

The other topics covered in the module dealt with hand spans (measuring angles with your hands), views (side and top) and the field of vision.

Of this first encounter with RME, the teacher who implemented the module expressed concern about the time needed for the activities, their impact on curriculum coverage, the connection with the actual content of the curriculum and the manner

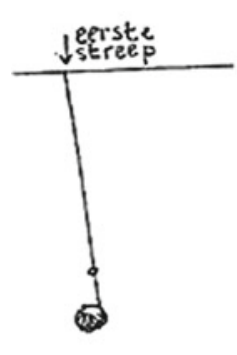

(1)

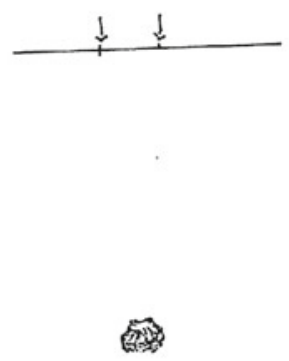

(2)

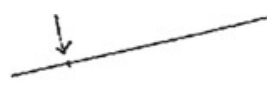

-

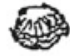

(3)

Fig. 5.1 Activities 1, 2 and 3 of the first worksheet on vision geometry ('eerste streep' = first line) 


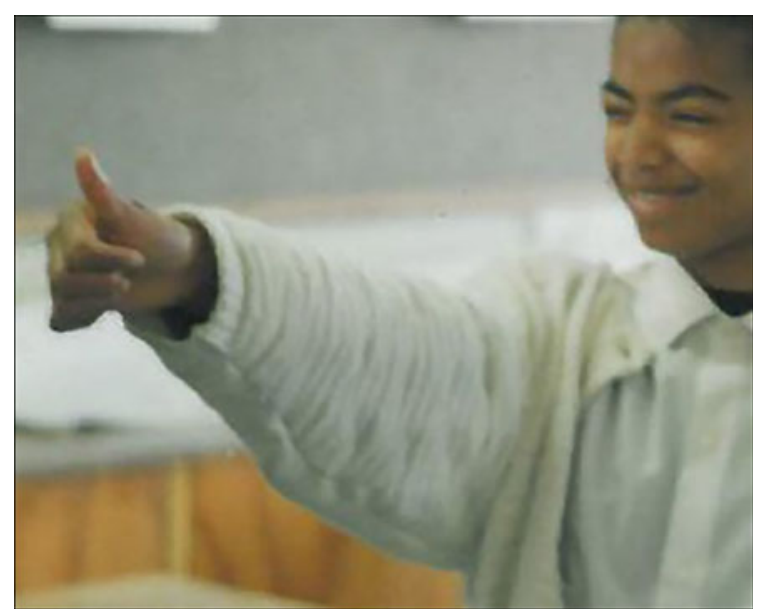

Fig. 5.2 Learner doing the 'Thumb jump' activity
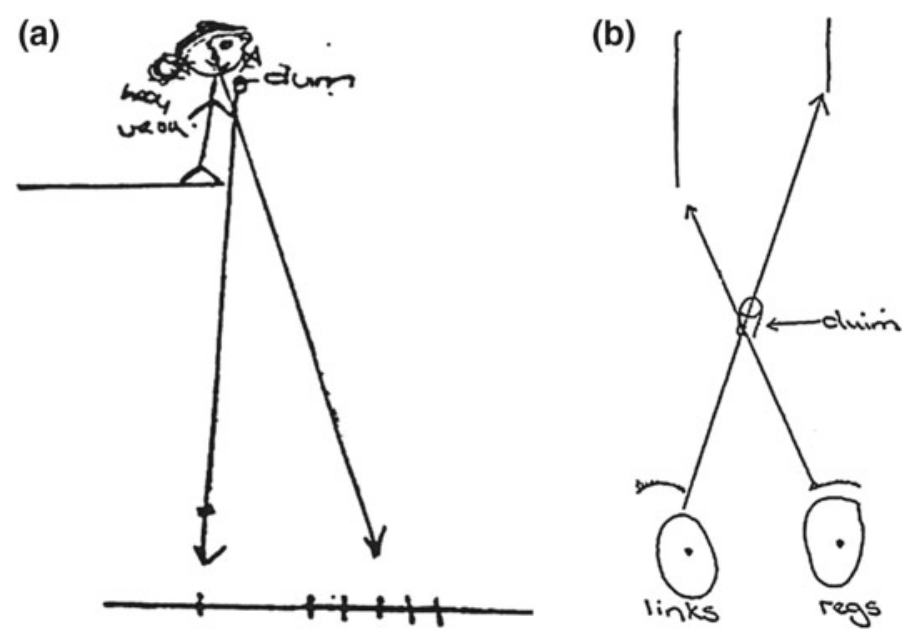

Fig. 5.3 Drawings made by one learner (writing on the left is illegible; 'duim' = thumb; 'links' = left; 'regs' = right]

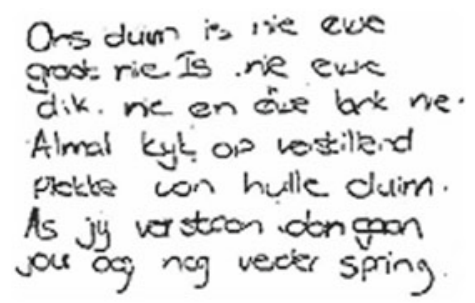

Our thumps are not the same size.

Not of the same thickness.

Every one looks from different locations from their thumps. If you stand further away then your eye jumps still further.

Fig. 5.4 Explanation of the thumb jump phenomenon 
in which the work will be examined since learners will eventually be "confronted with an examination" (Lewis, 1994, p. 69).

Based on the aforementioned feedback from the teacher and observations of the designers, the module was revised, as is characteristic of developmental research. One of the major changes made was to link the experimental work related to vision geometry to aspects of triangle geometry, which is an explicit topic mentioned in the South African curriculum for 12- to 13-year-olds (Grade 8). This led to a starting point different from the 'Thumb jump' activity and was linked to placing an object between two others so that the three are in line as given in Fig. 5.5.

The 'Thumb jump' activity was also more explicitly connected to aspects of the curriculum. One exercise, for example, was "Make a sketch of the thumb jump so that you get two isosceles triangles" and another one was "Make a sketch of the thumb jump so that you get two right-angles triangles." Figure 5.6 is representative of learners' responses to these exercises.

Experimental activities such as the above led to further exercises on classification of triangles. Overall the second cycle of the developmental research activity rendered materials which were more aligned to the curriculum that was operative in South Africa. The time to complete the activities was also addressed through a strategy of

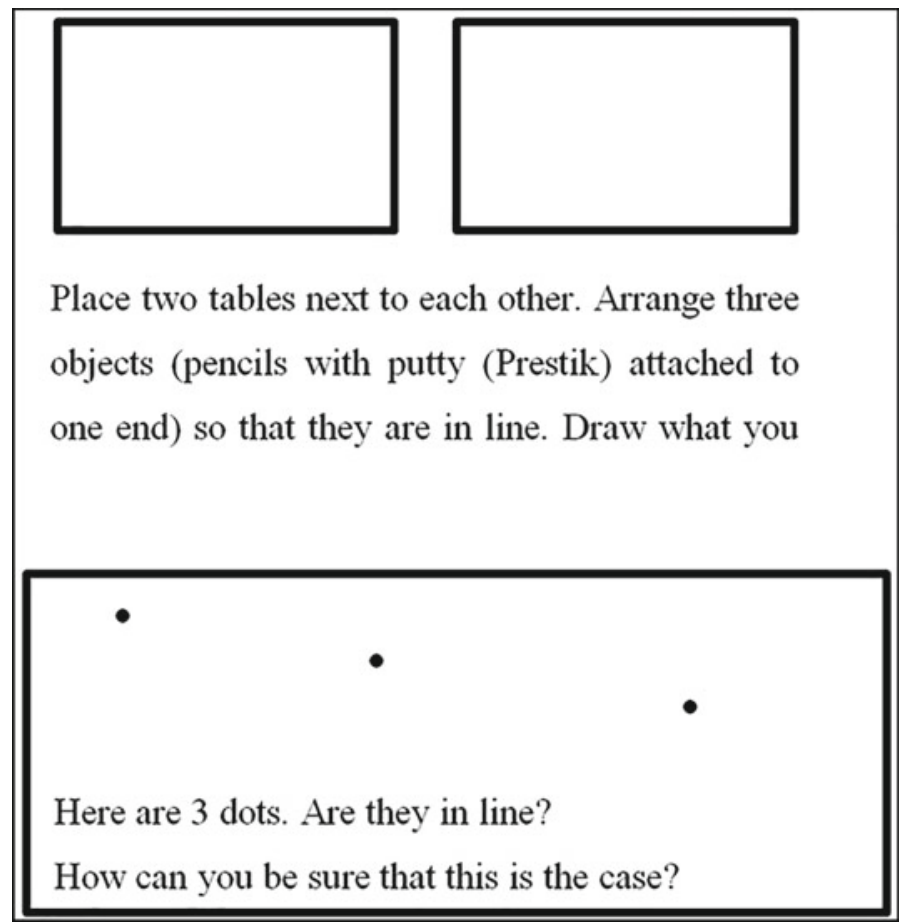

Fig. 5.5 Excerpts of initial activities of revised module 

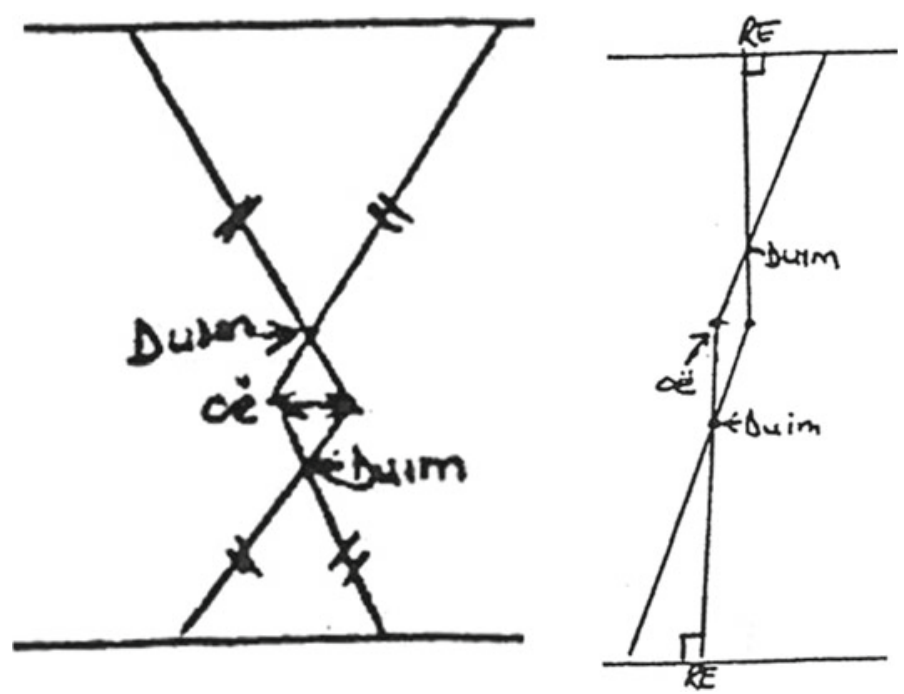

Fig. 5.6 Responses of the learners to the activities about the triangles ('duim' = thump, 'oë' = eyes, 'RE' = right angle)

providing the implementing teacher, different from the one who implemented the first cycle, with more guidance in the teacher guide that accompanied the activities.

The 'Thumb jump' activity was found enjoyable, exciting and not above their abilities by the learners. It was the first time they could use immediate experiences gained through experiments to engage with geometry. The scepticism of the implementing teacher, however, remained and as mentioned above, still revolved around the time needed for the activities, curriculum coverage and examinability of the module's content. Furthermore, there was no dissemination of the module to a wider group of teachers, other than to the two implementing teachers and the teacher who was involved in the development research aspect of this initial encounter with RME. The last-mentioned teacher contended that RME offers great possibilities for the realisation of an education in mathematics for fostering learner-centredness and nonauthoritarian ways of working classrooms. This was the kind of learning and teaching that was desired by the first democratically elected government in the country. Despite this, vision geometry had very little traction for impacting on the further curriculum development initiatives in the country. This finding points to tension between the REMESA module content and 'legitimate school mathematics', that is, the mathematics that is valued in high-stakes examinations (Julie, 2012; Kvale, 1993). In current policy documents and learning materials, the major ideas of the module on vision geometry are virtually invisible. 


\section{FILLING OF VASES}

Mum asked me to fill the three vases below with water. Each vase was held under a tap dripping slowly at a constant rate.

- Match the gives vases below $(1,2$ or 3 ) with a graph (A, B or C) of your choice.

- Explain your choice to your partner, then write it down.

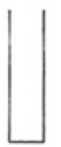

1

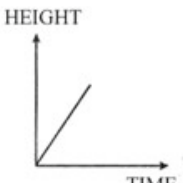

A
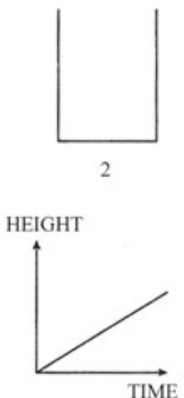

B

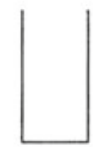

3

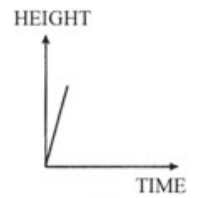

$\mathrm{C}$

Fig. 5.7 The REMESA-developed activity for the module Global Graphs

\subsection{Global Graphs}

The development of the module Global Graphs and the associated teaching experiments occurred when there was a more stable, albeit contested, operative curriculum in the country. For the junior school phase-Grades 7-9 (13- to 15-year-olds) - the name of the subject was changed to Mathematics, Mathematical Literacy and the Mathematical Sciences. This name change was to develop awareness that school mathematics does not only deal with pure mathematics, but also with applied mathematics, mathematical modelling, and probability and statistics. Furthermore, the revised curriculum was still underpinned by an outcomes-based education philosophy and, as alluded to before, 'subjects' were renamed as 'learning areas'. The module Global Graphs was an adaptation of activities developed by the Freudenthal Institute on graphs (Roodhardt et al., 1990). This resemblance can be observed in the REMESA activity 'Filling vases' in Fig. 5.7 and Roodhart and his colleagues' activity shown in Fig. 5.8. There are some differences. The REMESA-developed activity, for example, starts by requesting learners to fit graphs to similar vases with different dimensions whilst the activity from the Freudenthal Institute requires the construction of graphs fitting different containers. This difference resulted from discussions between the South African project workers and those from the Freudenthal Institute. The South African participants felt that the graph-fitting situation would be a more appropriate introductory activity for the module of study. 
Some water is poured into this glass. Afterwards the level of the water is measured. That results in this graph.
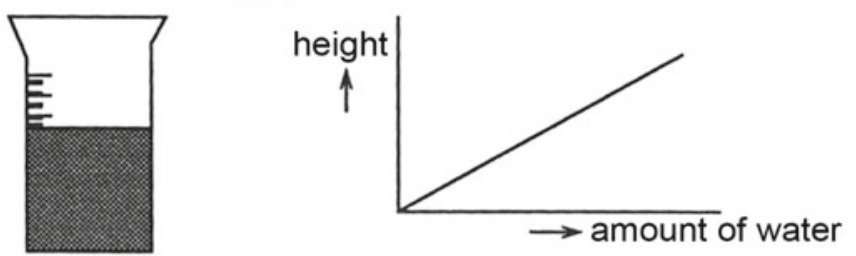

$>$ a How can you explain that the graph is a straight line?

$>$ b Draw global graphs for the round glasses for which the side view is shown.

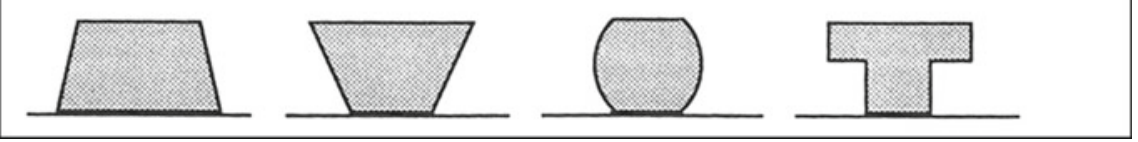

Fig. 5.8 Activity developed at the Freudenthal Institute for the unit Tabellen, Grafieken, Formules 2 (Roodhart et al., 1990)

Fig. 5.9 Visual fit of graphs in vases

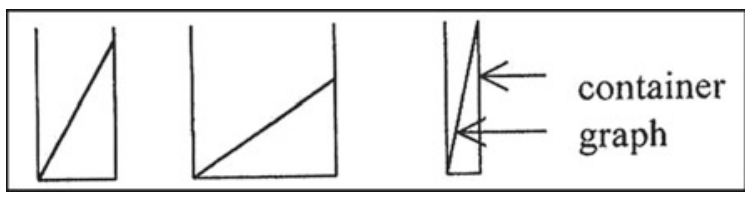

Different from the development of the module Vision Geometry, the development of Global Graphs was done with a larger group of practising teachers. Some of the teachers involved in the development of the module were also the implementers of the module in their classrooms. The module was implemented in a larger and more diverse classrooms, in terms of language (Afrikaans, IsiXhosa and English-firstlanguage speakers). Julie et al. (1998) describe the development and implementation of the module as follows.

The participating teachers wrote 'stories' about learners' handling of the activity. The major issues emerging regarding learners' dealing with activities from the stories were:

(a) The visual fit of the graphs in the vases as shown in Fig. 5.9.

(b) Reference by learners to a slow and fast rise.

(c) Conjecturing such as "the narrower the glasses the quicker they got filled" (Julie et al., 1998, p. 39).

Overall, teachers expressed satisfaction about the usefulness of the module Global Graphs. They wrote: 
As teachers we feel that these activities have value for all grades in the secondary school. It opened up meaning of a straight line to those that had dealt with it. It can also be valuable for the introduction of the straight line graph. And lastly, engagement in talking about slow rise, slower rate and faster rate provided learners with the opportunity to grapple with the concept of gradient. (Julie et al., 1998, p. 39)

Furthermore, the module was deemed appropriate for the outcomes-based operative curriculum. Comparing the acceptance of the module Global Graphs with that of Vision Geometry, the former had more traction. This can be ascribed to the proximity of graphical representations in all versions of the South African curriculum since the transition to a democratic dispensation. For example, in the latest version of the curriculum, the prominence of graphical representations as encapsulated in the module Global Graphs is captured as "[I]nvestigate the properties of graphs illustrating reallife relationships e.g., time-distance graphs" (Department of Basic Education, 2010, p. 39). The more readily acceptance of the module Global Graphs is also linked to its inclusion in textbooks with possible suggestions for its use in formal assessments. In the textbook Platinum Mathematics an activity similar to the vases is included under the section "Interpreting Graphs" (Bowie et al., 2012, p. 165). The formal exemplar test section of the same textbook (ibid., p. 200), also has items which are similar to those dealt with in the module Global Graphs.

\subsection{Conclusion}

Focusing on the design and teaching experiments related to two modules underpinned by the RME philosophy it was demonstrated that the reigning curriculum milieu impacted differentially on the appropriation by teachers of the learning resources. In this regard, the proximity, as perceived by teachers, of the materials to the operative curriculum plays an important role with respect to teachers' adoption of the resources for their practice. This is linked to the idea of immediacy for practice of any innovation. Teachers do want to be assured of the immediate relevance of innovations to their current responsibilities and accountabilities with respect to the curriculum and accompanying activities such as examinations. If this relevance is remote, as with the module Vision Geometry, the appropriation is low. On the other hand, if the relevance is near to the operative curriculum and further cemented by other boundary objects such as available textbooks, as it is more the case with the module Global Graphs, then the possibility of appropriation is higher.

These considerations led some of the original participants in the REMESA initiative to incorporate these insights into a current initiative related to the development of teaching mathematics in secondary schools. Central to this initiative is the participation of teachers as major role-players in collaboration with university-based mathematics educators, mathematicians and mathematics curriculum advisors. This is in line with Burkhardt's (2006, p. 196) suggestion that "typical teachers in realistic circumstances" participate in initiatives as active and respected participants to work towards the improvement of mathematical education in schools. The initiative 
referred to is highly driven by the developmental research approach underpinning the work of the Freudenthal Institute. It is thus our contention that the residual effect of the REMESA project is contributing positively to current research and development endeavours to address the issue of high-quality teaching of mathematics in secondary schools in low socio-economic environments in a region in South Africa.

\section{References}

Bowie, L., Cronje, E., Heany, F., Maritz, P., Olivier, G., Rossouw, B., \& Willemse, S. (2012). Platinum mathematics. Cape Town, South Africa: Maskew Miller Longman (PTY) Ltd.

Burkhardt, H. (2006). From design research to large-scale impact: Engineering research in education. In J. van den Akker, K. Gravemeijer, S. McKenney, \& N. Nieveen (Eds.), Educational design research (pp. 121-150). London, UK: Routledge.

Department of Basic Education. (2010). Curriculum and assessment policy statement (CAPS) Mathematics: Senior phase. Pretoria, South Africa: Department of Basic Education.

Freudenthal, H. (1973). Mathematics as an educational task. Dordrecht, the Netherlands: Reidel.

Hiebert, J., Carpenter, T., Fennema, F., Fuson, K., Human, P., Murray, H., et al. (1996). Problem solving as a basis for reform in curriculum and instruction: The case for mathematics. Educational Researcher, 25(4), 12-21.

Jansen, J. (1999). The school curriculum since apartheid: Intersections of politics and policy in the South African transition. Journal of Curriculum Studies, 31(1), 57-67.

Julie, C. (1998). Ideal and reality: Cross-curriculum work in school mathematics in South Africa. ZDM Mathematics Education, 30(4), 110-115.

Julie, C. (2012). The primacy of teaching procedures in school mathematics. In S. Nieuwoudt, D. Laubser, \& H. Dreyer (Eds.), Proceedings of the 18th Annual National Congress of the Association for Mathematics Association of South Africa (pp. 16-31). Potchefstroom, South Africa: NorthWest University.

Julie, C., Cooper, P., Daniels, M., Fray, B., Fortune, R., Kasana, Z., et al. (1998). Global graphs: A window on the design of learning activities for outcomes-based education. Pythagoras, 46(47), $37-44$.

Kvale, S. (1993). Examinations re-examined: Certification for students or certification of knowledge? In J. Lave \& S. Chaiklin (Eds.), Understanding practice: Perspectives on activity and context (pp. 215-240). Cambridge, UK: Cambridge University Press.

Lewis, H. A. (1994). 'n Ontwikkelingsondersoekstudie na realistiese meetkunde on ondderig in standard ses [A developmental research study on realistic geometry teaching in standard six (Grade 8)]. Unpublished master's thesis. Bellville, South Africa: University of the Western Cape.

Roodhardt, A., Hauchart, C., De Jong, J., Van der Kooij, H., De Lange, J., \& Van Reeuwijk, M. (1990). Tabellen, grafieken, formules 2 [Tables, graphs, formulas 2] . Utrecht, the Netherlands: Freudenthal Institute, Utrecht University.

Roper, T. (1994). Integrating mathematics into the wider curriculum. In A. Orton \& G. Wain (Eds.), Issues in teaching mathematics (pp. 174-191). London, UK: Cassell.

Selkirk, K. (1982). Links between mathematics and other subjects. In M. Cornelius (Ed.), Teaching mathematics (pp. 186-213). London, UK: Croom Helm.

Verhage, H., Adendorff, S., Cooper, P., Engel, M., Kasana, Z., Le Roux, P., et al. (2000). The interrelationship between graphs, formulae and tables: Exploring the relationship between mathematising and outcomes-based education. Pythagoras, 51, 33-42. 
Open Access This chapter is distributed under the terms of the Creative Commons Attribution 4.0 International License (http://creativecommons.org/licenses/by/4.0/), which permits use, duplication, adaptation, distribution and reproduction in any medium or format, as long as you give appropriate credit to the original author(s) and the source, a link is provided to the Creative Commons license and any changes made are indicated.

The images or other third party material in this chapter are included in the work's Creative Commons license, unless indicated otherwise in the credit line; if such material is not included in the work's Creative Commons license and the respective action is not permitted by statutory regulation, users will need to obtain permission from the license holder to duplicate, adapt or reproduce the material. 